\title{
LAS REPERCUSIONES DE LA GUERRA SOBRE LOS PRIVILEGIADOS Y LA ASISTENCIA AL MONARCA: EL ESCUADRÓN DE LA NOBLEZA (1641-1643) ${ }^{1}$
}

\author{
Agustín JiMÉNEZ MORENO \\ Universidad Complutense
}

\begin{abstract}
RESUMEN: La relación entre la Corona y el estamento privilegiado durante el reinado de Felipe IV, y en concreto durante el ministerio del Conde Duque de Olivares, constituye una de las materias que más controversia ha despertado entre los historiadores. La tesis que ha prevalecido hasta los últimos años era la de una nobleza abúlica y perezosa, cada vez más alejada de la actividad que proporcionaba validez legal a sus privilegios: la profesión de las armas. En este artículo nos proponemos demostrar el poco rigor de tales planteamientos, y como el segundo estamento no dio la espalda al monarca en la difícil coyuntura de principios de la década de los 40 del siglo XVII.
\end{abstract}

PALABRAS CLAVE: Nobleza, Caballería, Servicio Militar, Reclutamiento, Hidalgos, Caballeros de Hábito.

ABSTRACT: Relationships between Crown and privileged class during Philip IV's reign, in particular during Count Duke of Olivares' ministry, is a subject that has aroused most controversy among historians. Until recent years the most common opinion was that of a supine and lazy nobility had lost its commitment to service and was increasingly divorced from activity that gave legal validity to their privileges: the war. In this article we propose to show how little rigor of such approaches, and as the second estate did not give back to the monarch in early 40s of seventeenth century.

KEYWORDS: Nobility, Cavalry, Military Service, Recruitment, Hidalgos, Knights of Military Orders.

Uno de los apriorismos que más ha determinado la concepción de los nobles castellanos durante el Seiscientos, es su alejamiento de la actividad que justificaba su preeminencia en la sociedad: la guerra ${ }^{2}$. Esta aseveración se ha visto reforzada por los planteamientos de parte de la intelectualidad de la época, tanto profesionales de las armas como individuos sin relación con la milicia, para

${ }^{1}$ Recibido el 31 de agosto de 2011. Aceptado en el Consejo de 8 de noviembre de 2011.

2 Domínguez Ortiz, A. (1955). «La movilización de la nobleza castellana en 1640». Anuario de Historia del Derecho Español, 25, pp. 729-823. WRIGHT, L.P. (1982). «Las Órdenes Militares en la sociedad española de los siglos XVI y XVII. La encarnación institucional de una tradición histórica». En Elliott, J.H (ed). Poder y sociedad en la España de los Austrias. Barcelona, Crítica, pp. 15-56. 
quienes desde los años finales del reinado de Felipe II, el nexo que unía ambas realidades se hallaba cada vez más debilitado. Pero esta visión tan negativa, y hasta cierto punto injusta, del estamento privilegiado está siendo revisada en la actualidad $^{3}$. Si bien el grado de colaboración varía mucho dependiendo del caso, la nobleza como grupo no permaneció al margen de la contienda en la que se vio inmersa la monarquía española a partir de 1635, y sobre todo a partir de 16381639, cuando la península ibérica pasó a ser testigo de las hostilidades con Francia.

En cuanto a la forma en la que los privilegiados podían contribuir al esfuerzo bélico común, abarca un amplio abanico de posibilidades. Entre ellas destaca su capacidad movilizadora y financiera. Pero junto a estas modalidades de servicio de carácter indirecto también se encontraba la asistencia en persona. No obstante, su principal atractivo (más que el estrictamente militar) era el beneficioso ejemplo que tendría en el resto de la sociedad la presencia de los privilegiados en el campo de batalla.

Según nuestro criterio esta fue la principal motivación que se encontraba detrás de la formación del Escuadrón de la Nobleza, así como de otra unidad de marcado carácter nobiliario: el Batallón de las Órdenes ${ }^{4}$. Lo cierto es que en esa delicada

${ }^{3}$ Por ejemplo: MACKAY, R. (2007). Los límites de la autoridad real. Resistencia y obediencia en la Castilla del siglo XVII. Valladolid, Junta de Castilla y León, pp. 115-149. (1 ${ }^{a}$ edición inglesa: Cambridge University Press, 1999). SAlAS Almela, L. (2001). «Las espadas del rey: nobleza territorial en Castilla en el siglo XVII». Campo de Calatrava, 3, pp. 101-114. Hernández FranCo, J. Molina PuCHE, S. (2004). «El retraimiento de la nobleza castellana con motivo de la guerra francoespañola (1635-1648). El ejemplo contrapuesto del Reino de Murcia». Cuadernos de Historia Moderna, 29, pp. 111-130. THOMPSON, I.A.A. (2007). «Consideraciones sobre el papel de la nobleza como recurso militar en la España Moderna». En Jiménez Estrella, A. y ANDUJAR CASTILlo, F. (eds). Los nervios de la guerra. Estudios sociales sobre el ejército de la Monarquía Hispánica (siglos XVI-XVIII): nuevas perspectivas. Granada, Comares, pp. 15-35. JIMÉNEZ MoRENO, A. (2009). «En busca de una nobleza de servicio. El Conde Duque de Olivares, la aristocracia y las Órdenes Militares (1621-1643)». En RIVERO RODRÍGUEZ, M. (coord.). Nobleza hispana, nobleza cristiana. La Orden de San Juan. Vol. I. Madrid, Polifemo, pp. 209-256.

${ }^{4}$ Véase: Postigo Castellanos, E. (1989). «Notas para un fracaso: la convocatoria de las Órdenes Militares. 1640-1645». Las Órdenes Militares en el Mediterráneo Occidental (s. XIII-XVIII). Madrid, Casa de Velázquez. Instituto de Estudios Manchegos, pp. 397-414. FERNÁNDEZ IzQUIERDO, F. (2004). «Los caballeros cruzados en el ejército de la Monarquía Hispánica durante los siglos XVI y XVII: ¿anhelo o realidad?» Revista de Historia Moderna. Anales de la Universidad de Alicante, 22, pp. 11-60. JimÉNEZ MoRENO, A. (2009). «Poder central y poderes locales. El cumplimiento de la convocatoria de los caballeros de hábito del año 1640 en Jerez de la Frontera». En BRAvo CARo, J.J. y Villas Tinoco, S. (eds.). Tradición versus innovación en la España Moderna. Vol. II. Málaga, Fundación Española de Historia Moderna, pp. 705-728. JimÉnEZ Moreno, A. (2011). Nobleza, guerra y servicio a la Corona. Los caballeros de hábito en el siglo XVII [recurso electrónico]. (Tesis 
situación la presencia de los privilegiados en el campo de batalla (aunque fuera en unas condiciones muy especiales), podría servir para justificar los sacrificios que la Corona estaba exigiendo a sus súbditos, y cuya intensidad se mantendría durante los años siguientes. De este modo, en los últimos días de 1640 y los primeros de 1641, con motivo de una hipotética salida del rey hacia Extremadura para encabezar las fuerzas que debían sofocar la incipiente defección portuguesa, se decidió prevenir a los hidalgos para que acompañaran a Felipe IV. Al igual que en otros proyectos tendentes a vincular al estamento nobiliario con el servicio militar, detrás de todo se encontraba la mano del Conde Duque de Olivares, para quien esta materia constituyó una de sus prioridades de gobierno, según se puede ver en su famoso Gran Memorial de $1624^{5}$.

Para dar forma a la movilización de los hidalgos Olivares optó por uno de sus métodos favoritos: la constitución de una junta poco numerosa, compuesta por individuos de su círculo de colaboradores. Al frente se situó su sobrino, D. Luis de Haro, auxiliado por D. Francisco Zapata, D. Jerónimo de Villanueva (protonotario de Aragón) y el marqués de la Hinojosa (también conde de Aguilar), mientras que D. Cristóbal de Medina ejercería las funciones de secretario. Según sus cálculos se esperaba movilizar a cerca de dos millares de hidalgos, y lo que es más importante, casi sin coste para la Real Hacienda pues servirían sin sueldo ${ }^{6}$.

Desde sus primeros momentos de vida, la Junta del Escuadrón de la Nobleza tuvo choques con la del Batallón de las Órdenes (también conocida como Junta de la Milicia de las Órdenes), que se encargaba de la movilización de los caballeros de hábito, y ya había conseguido formar un cuerpo de caballería, que en esos momentos prestaba servicio en el frente catalán. No obstante, la pugna se circunscribía a una serie de supuestos, muy concretos, sobre los que ambas instituciones creían tener competencias. Uno de ellos eran los caballeros que en 1640 habían entregado un sustituto que se presentara en su lugar (pues se había determinado relevarles de acudir en persona, bien por edad, problemas de salud o porque su ocupación se lo impedía). Según la Junta de las Órdenes se trataba de una relevación provisional, que solo les liberaba de cumplir con su obligación de forma interina, y una vez que pudieran hacerlo deberían sentar plaza en el Batallón. A pesar de esta circunstancia, algunos de ellos se alistaron en el Escuadrón de la

doctoral inédita dirigida por el Dr. Adolfo Carrasco Martínez, defendida en la UCM en octubre de 2010). [Consultado: 1-7-2011].

${ }^{5}$ Elliott, J.H. y DE La PeÑA, J.F. (1978-1981). Memoriales y cartas del Conde Duque de Olivares. Tomo I. Madrid, Alfaguara, pp. 58-61.

${ }^{6}$ Baltar Rodríguez, J.F. (1998). Las juntas de gobierno en la Monarquía Hispánica. Madrid, Centro de Estudios Políticos y Constitucionales, pp. 390-392. 
Nobleza, aspecto que constituía una paradoja, pues si no tenían ningún deseo de empuñar las armas, parece sorprendente que ahora, de forma espontánea, estuvieran dispuestos a hacerlo. Por este motivo, la Junta de las Órdenes solicitó que, si en realidad deseaban asistir al rey en persona, lo hicieran donde les correspondía (en el Batallón ${ }^{7}$ ). Si bien se trataba de una decisión controvertida, el monarca resolvió que todos aquellos caballeros de hábito que dieron sustituto, pero que ahora desearan servir en persona en el Escuadrón de la Nobleza, pudieran hacerlo, pasando a depender de la entidad administrativa presidida por D. Luis de Haro $^{8}$.

Otro de los puntos de fricción vino motivado por los individuos que con anterioridad al 14 de enero de 1641 (fecha límite para determinar en cual de las dos unidades debían asistir) sentaron plaza en el Escuadrón, pero que en los días siguientes ingresaron en las Órdenes Militares ${ }^{9}$. La disputa se dirimió a favor de la Junta del Escuadrón de la Nobleza, estipulándose que los sujetos en cuestión podían prestar servicio por esta vía, y una vez hubieran cumplido en ella ya se vería lo que se decidía. De todos modos, lo máximo que el organismo reclutador de los caballeros de hábito les podría exigir era la presentación de un sustituto ${ }^{10}$.

Sin embargo, la Junta de la Milicia de las Órdenes no estaba dispuesta a perder su jurisdicción sobre los nuevos caballeros, pues estos debían presentar una fianza con anterioridad al despacho del hábito, para garantizar que antes de un mes sirvieran en el Batallón ${ }^{11}$. Pero lo cierto es que ese organismo no deseaba ver

${ }^{7}$ Consulta de la junta de la milicia de las Órdenes, para que V.M. se sirva de advertirla de lo que ha de obrar con los caballeros de hábito, por excusarse algunos a causa de estar prevenidos por la que se hace en el aposento del conde duque. Madrid, 28-1-1641. Archivo Histórico Nacional (En adelante AHN), Órdenes Militares (En adelante, OO.MM), Leg. 4667.

8 “(...) Y los [caballeros de hábito] que han dado sustitutos y voluntariamente se les pide me vayan sirviendo, ha de correr por la junta del escuadrón de la nobleza.” Ibídem.

${ }^{9}$ Ibídem.

10 “(...) Y los que han tomado después acá los hábitos, y los previniere la junta del Escuadrón, parece cumplen, pues no se les puede obligar más de que vayan con sus personas. Y acabada la ocasión se verá si hubieran de dar sustitutos." Ibídem.

11 “(...) Y en la tercera y última [parte] se encuentra reparo y parece que tiene inconveniente. Porque los caballeros que después [de alistados en el Escuadrón de la Nobleza] han tomado los hábitos, deben cumplir aquí. Y así, se ha ido haciendo diligencia con los que han entrado de nuevo, y que antes de recibir los hábitos aseguren con fianza que, precisamente, dentro de un mes se presentarán a servir. (...) Y la primera obligación del caballero de hábito es ir con su orden en persona, y esta sólo se dispensa por ocupación o impedimento justo" Consulta de la junta de la milicia de las Órdenes en la que representa lo que se le ofrece sobre los caballeros que recibieron los 
invadidas sus competencias, ya que su objetivo era monopolizar el servicio militar de los caballeros cruzados. Del mismo modo, era muy probable que toda esta parafernalia no fuera sino una argucia para evitar su participación personal, y en el peor de los casos quedar obligados a la presentación de un sustituto ${ }^{12}$. Por otra parte, tampoco podemos descartar que el deseo de servir en el Escuadrón de la Nobleza se debiera a que por esta vía esperaban obtener mayores recompensas. En este sentido, había una gran diferencia entre un servicio forzoso y otro voluntario, tanto en términos de estimación como de resultados prácticos, ya que a la hora de solicitar recompensas siempre estaría mejor valorada la asistencia espontánea que la impuesta, pues en este último supuesto no se trataba más que del cumplimiento de una obligación contraída.

El malestar de la Junta de la Milicia de las Órdenes motivó que se impusiera cierto orden, consiguiendo que los nuevos caballeros, y los que fueran ingresando en las Órdenes Militares en los meses siguientes, quedaran bajo su dominio. Con ellos se pretendía formar una compañía que sería enviada a Mérida, ciudad designada como plaza de armas de las fuerzas encargadas de devolver a la obediencia a los rebeldes ${ }^{13}$.

Por su parte, la Junta del Escuadrón de la Nobleza defendió su pretensión de que los nuevos caballeros de hábito residentes en Madrid (en principio solo aspiraba a registrar a los caballeros de la Corte que se encontraran en las dos situaciones anteriormente referidas. No obstante, acarreaba tener jurisdicción sobre más de la mitad de los recién ingresados en las milicias cristianas, pues la mayoría residían en ella, o habían recibido el hábito por patria común en la capital), pudieran servir en esa unidad sin ningún tipo de limitación, así como los que dieron sustitutos para el Batallón y ahora desearan servir en persona ${ }^{14}$. Del mismo modo

hábitos, una vez habían sentado plaza en el Escuadrón de la Nobleza. Madrid, 26-2-1641. AHN, OO.MM, Leg. 4667.

12 “(...) Y así, lo que se pone en una parte, se quita a otra donde toca, sin que se aumente mayor número. Y entiende la junta que sólo servirá de que los caballeros consigan no cumplir en ninguna, pues habiendo salido de la que es más precisa, y donde se tiene más noticia de ellos, les será fácil en la junta del Escuadrón de la Nobleza, donde solamente se llama para ofrecimiento voluntario." Ibídem.

13 Ibídem.

14 “(...) Y esta junta representa a V.M. que los caballeros que después de acá hubieren tomado los hábitos, que no han ido con estandartes, ni dado sustitutos, y ofrecen por esta junta ir sirviendo personalmente en este batallón, parece que cumplen, pues no se les puede obligar a más que ir en persona. Y acabada la ocasión, se podrá ver si han de pasar con los estandartes de su orden, o dar sustitutos, porque si a esta junta se quitasen los caballeros que dieron sustitutos, y ahora voluntariamente han ofrecido ir, y los que después han tomado los hábitos, fueran muy pocas las 
expresó su malestar con la resolución adoptada a finales de febrero, que disponía la formación de una compañía de las Órdenes Militares con todos los caballeros que habían recibido el hábito después de haberse alistado en el Escuadrón de la Nobleza pues, según su criterio, las obligaciones inherentes a la condición nobiliaria eran superiores a las que llevaba implícita la pertenencia a las milicias católicas, "ya que la obligación de la sangre es superior a la del hábito"15. Con esta decisión se socavaría una de las bases que sustentaba la formación del Escuadrón: el prestigio y la sensación de pertenencia a una elite.

También se producirían importantes daños en lo relativo a su organización y operatividad, pues al parecer ya se había comenzado a formar las compañías. Además, no podemos obviar el papel jugado por las relaciones personales y clientelares, tan importantes a la hora de llevar a cabo los reclutamientos. Para la Corona tal vez fuera poco relevante que sirvieran en una $\mathrm{u}$ otra unidad, pero los interesados tenían una opinión muy diferente, ya que muchos de ellos se habían alistado en el Escuadrón de la Nobleza movidos por lealtades de esa índole, sabiendo que serían asistidos por sus patrones, más que por un deseo de servir al monarca $^{16}$.

Pese a que, al menos en teoría, se había llegado a um acuerdo en esta materia, siguieron produciéndose conflictos entre ambos organismos sobre las competencias que debían asumir y los individuos que podían movilizar. En esta ocasión se trataba de algunos caballeros de hábito que tenían sentada plaza en el Batallón, pero que a la conclusión de la campaña del año 1640 se habían alistado en el Escuadrón de la

personas que quedarán de lustre para el escuadrón. (...) Demás de que esto es solamente para lo que toca a los caballeros que asisten en la Corte, porque los demás corren por su cuenta [por la junta de la milicia de las Órdenes]". Consulta de la junta del Escuadrón de la Nobleza sobre la forma en que han de servir los caballeros de las órdenes militares que, después de dar sustitutos, han decidido ir en persona en el, y aquellos que han tomado los hábitos recientemente. Madrid, 3-4-1641. AHN, OO.MM, Leg. 4667.

${ }^{15}$ Consulta de la junta del Escuadrón de la Nobleza, sobre lo que V.M. tiene resuelto sobre la forma en que deben servir quien han tomado los hábitos luego. Madrid, 13-4-1641 AHN, OO.MM, Leg. 4667.

16 “....) Siendo capitanes de estas compañías los primeros vasallos de estos reinos, y que muchos de los caballeros de hábito son personas conocidas y dependientes de ellos, sentirán se les quiten de ellas, pues no se puede dudar que con ellos van más lucidas las compañías, y quizás, socorridos a su sombra y debajo de su protección, podrían hacer más decorosamente esta jornada y servir con mayor valor, pues la falta de caudal siempre envilece y abate el mayor valor." Ibídem. 
Nobleza, abandonando su puesto sin permiso ${ }^{17}$. Este hecho era de una gravedad extrema, pues se trataba de uno de los delitos más graves que contemplaba la justicia militar. No obstante, las circunstancias exigían cierta relajación de la disciplina, pues el objetivo era conseguir su asistencia, quedando en un segundo plano (desde el punto de vista de la Corona) el lugar donde lo hicieran.

Finalmente se repitieron los mandatos promulgados en los meses anteriores; es decir, los caballeros de hábito que en su momento dieron sustituto, pero que ahora desearan servir en persona en el Escuadrón de la Nobleza, así como quienes sentaron plaza en dicha unidad, y con posterioridad fueron honrados con el ingreso en las milicias cristianas, podrían hacerlo con libertad. Mientras que la Junta de la Milicia de las Órdenes sólo podría compeler a los caballeros que en el llamamiento de 1640 no habían servido en persona ni tampoco presentaron sustituto ${ }^{18}$.

De esta forma, pese a que los nuevos caballeros eran muy necesarios para reponer las bajas sufridas por el Batallón durante su primera campaña, no le quedó más remedio que reconocer su fracaso y reconocer que la Junta del Escuadrón de la Nobleza tenía jurisdicción sobre ellos. También se vio obligada a asumir que quienes ingresaron en las Órdenes Militares tras alistarse en el Escuadrón, no debían abonar los 300 ducados correspondientes a su sustituto ${ }^{19}$.

Pero al tiempo que se apremiaba a los hidalgos, el secretario Cristóbal Medina remitió una serie de misivas a diferentes nobles titulados. En ellas, como consecuencia de la extrema urgencia en la que se encontraba la monarquía española, se les notificó la resolución de Felipe IV de dirigirse al frente, circunstancia que obligaba al segundo estado, en bloque, a acompañarle ${ }^{20}$.

Como ya hemos mencionado, una de las opciones más interesantes que presentaba la participación de los privilegiados en la guerra era su función movilizadora. Junto a ella se encontraba su capacidad financiera, gracias a la cual, al más puro estilo de los señores feudales, podía hacer frente al sustento de su hueste. Si tenemos en cuenta estas circunstancias, no puede sorprender que algunos

${ }^{17}$ Consulta de la junta de la milicia de las Órdenes sobre lo que resolvió V.M. sobre la forma en que se ha de guardar el servir los caballeros de hábito, en el Batallón de ellas o en el escuadrón de la Nobleza, y los que tocan a cada parte. Madrid, 15-4-1641. AHN, OO.MM, Leg. 4667.

${ }^{18}$ Ibídem.

${ }^{19}$ Consulta de la junta de la milicia de las Órdenes en la que dice lo que se le ofrece sobre los nobles que antes de tener hábito se alistaron en el Escuadrón de la Nobleza, y después le han recibido. Madrid, 27-4-1641. AHN, OO.MM, Leg. 4667.

${ }^{20}$ Carta del secretario Cristóbal Medina al marqués del Fresno. Madrid, 7-5-1641. Sección Nobleza del Archivo Histórico Nacional (En adelante SNAHN), Frías, 26/138. 
aristócratas intercedieran a favor de sus allegados, con el objetivo de que no fueran encuadrados en el Batallón de las Órdenes, y sirvieran en el Escuadrón en unidades comandadas por sus señores. Un ejemplo de ello lo tenemos en la actuación del duque de Pastrana, quien en estas circunstancias ofreció servir en el Escuadrón con una compañía de caballos ${ }^{21}$. A pesar de todo, la Junta de la Milicia de las Órdenes requirió a uno de sus deudos, D. Diego de Morquecho, quien recibió el hábito de la orden de Santiago con posterioridad a su registro en el Escuadrón, pero el organismo reclutador de los caballeros de hábito le compelió a alistarse en el Batallón.

Con todo, desde un punto de vista práctico lo mejor sería que D. Diego sirviera junto al duque de Pastrana, pues bajo su amparo y protección las condiciones del servicio mejorarían sustancialmente, ya que era responsable del mantenimiento de sus vasallos, quienes le auxiliarían en esta ocasión movidos por los lazos de dependencia que les unían más que por su lealtad a la Corona. Nos encontramos ante otra evidencia de lo que significaba la función reclutadora de la nobleza, inserta dentro de unas complejas relaciones clientelares donde el pago de favores y las remuneraciones jugaban un destacado papel.

De la misma manera, debemos tener en cuenta que el servicio militar personal en el Escuadrón de la Nobleza podía suponer para algunos privilegiados la posibilidad de obtener jugosas recompensas, sobre todo para mejorar su situación económica $^{22}$, o solicitar mercedes que de otra manera no hubieran podido alcanzar.

${ }^{21}$ Consulta de la junta del Escuadrón de la Nobleza sobre lo que representa el duque de Pastrana en cuanto a la pretensión de D. Diego Morquecho de Guzmán, caballero de la orden de Santiago. Madrid, 12-5-1641. AHN, OO.MM, Leg. 4667.

22 Sobre esta cuestión véase: JAGO, C. (1973). «The influence of debts on the relations between Crown and aristocracy in seventeenth-century Castile». The Economic History Review, 26/2, pp. 218236. JAGO, C. (1979). «The crisis of the aristocracy in the seventeenth-century Castile». Past and Present, 84, pp. 60-90. Yun CASALILlA, B. (1990). «La situación económica de la aristocracia castellana durante los reinados de Felipe III y Felipe IV». En ElliotT, J.H. y García SANZ, A. (coords). La España del Conde Duque de Olivares. Valladolid, Secretariado de Publicaciones de la Universidad de Valladolid, pp. 519-551. Yun CASALILLA, B. (1998). «Felipe II y el endeudamiento de la aristocracia, un avance». En RIBOT GARCíA, L. y BERENGUER, E. (coords). Las sociedades ibéricas y el mar a finales del siglo XVI. Tomo II. La Monarquía. Recursos, organización y estrategias. Lisboa, Sociedad Estatal para la conmemoración de los centenarios de Carlos V y Felipe II, pp. 59-80. YUN CASAlilla, B. (2002). La gestión del poder. Corona y economías aristocráticas en Castilla (siglos XVI-XVIII). Madrid, Akal. CARRASCO MARTíneZ, A. (1991). «Una forma de gestión de las haciendas señoriales en dificultades: los contratos de administración con hombres de negocios durante la primera mitad del siglo XVII». Cuadernos de Investigación Histórica, 14, pp. 87-106. ATIENZA HERNÁNDEZ, I. (1994). «La quiebra de la nobleza castellana en el siglo XVII. Autoridad y poder señorial: el secuestro de los bienes de la casa de Osuna». Hispania, 156, pp. 49-91. GARCía Hernán, 
Análogamente llama la atención la generosidad mostrada por la Corona, que no escatimó en medios a la hora de facilitar su participación en esta empresa, sobre todo en lo referido a la venta de bienes sujetos a mayorazgo, o la imposición de censos sobre ellos. El contrapunto lo encontramos en la actitud de la Cámara de Castilla, garante de la continuidad de esas herencias, que puso objeciones a la mayoría de las solicitudes, pues acarreaban una desmembración del patrimonio vinculado. Y cuando dio su beneplácito, fue con la condición de que la cantidad que se pretendía obtener no fuera superior al coste que supondría su servicio en el Escuadrón $^{23}$.

En cualquier caso, la Junta del Escuadrón de la Nobleza solicitó al monarca que la Cámara de Castilla acelerara los trámites administrativos, pues sin la liquidez suficiente no podrían acompañar al rey ${ }^{24}$. Sin embargo, el organismo encargado de refrendar las facultades concedidas por la Corona no actuó con la celeridad que exigía la situación, y se reiteraron los ruegos para que se apremiara al gobernador del Consejo de Castilla y se dinamizara su despacho ${ }^{25}$. Pese a las presiones recibidas la Cámara se mantuvo firme y expresó sus reservas a tramitar algunas pretensiones, ante los graves daños que podría ocasionar. Su principal temor era que los mayorazgos se vieran mermados, circunstancia que causaría graves perjuicios a los herederos. No obstante, si con ello se conseguía el objetivo que pretendía la Corona (que los fondos inmovilizados fueran empleados en la defensa de la monarquía), tal vez se pudiera hacer la vista gorda. Pero lo cierto es que,

D. (1994). «Las fuentes de ingresos de la aristocracia castellana bajo los Austrias». Torre de los Lujanes, 28, pp. 45-59. Martínez HernándeZ, S. (2003). «La hacienda del marqués de Velada. Perfiles de una economía cortesana, 1516-1616». Cuadernos de Historia Moderna, 28, pp. 35-70.

${ }^{23}$ Por ejemplo, la Cámara mostró su negativa a que D. Iñigo López de Mendoza vendiera unas casas sujetas al mayorazgo de que era titular, porque se trataba de la propiedad principal y supondría ir contra la voluntad del fundador. Así, recomendó que se le concediera facultad para imponer censos por un valor máximo de 3.000 ducados. En el caso de D. Francisco de Carvajal, D. Pedro González Mendoza, Ignacio Gómez de Mella y D. Diego de Rojas y Carvajal, se les obligó a presentar un informe en el que constara el valor real de sus mayorazgos, y según esa tasación se les permitiría tomar la cantidad suficiente para atender a este desembolso. Consulta de la Cámara sobre la facultad que V.M. se ha servido de conceder, por la junta del Escuadrón de la Nobleza, a D. Iñigo López de Mendoza, para vender unas casas de su mayorazgo. Madrid, 14-3-1641. AHN, Consejos, Leg. 4428, $\mathrm{n}^{\circ}$ 159. Consulta de la Cámara sobre las facultades que V.M. se ha servido conceder a (...) para vender censos y juros de sus mayorazgos, para los gastos que han de hacer sirviendo en el Escuadrón de la Nobleza. Madrid, 16-4-1641. AHN, Consejos, Leg. 4428, nº 34.

${ }^{24}$ Consulta de la junta del Escuadrón de la Nobleza sobre los medios ofrecidos a los caballeros hijosdalgo que salen a servir en la ocasión presente. Madrid, 3-5-1641. AHN, Estado, Leg. 6405(2).

${ }^{25}$ Consulta de la junta del Escuadrón de la Nobleza sobre la detención que hace la Cámara de los medios ofrecidos a los caballeros hijosdalgo que van a servir en el. Madrid, 11-6-1641. AHN, Estado, Leg. 6405(2). 
como bien sospechaba la Cámara, en la mayoría de los casos no sería más que una solución circunstancial, destinada a aliviar la falta de liquidez de los solicitantes, quienes emplearían la mayor parte de lo obtenido en gastos superfluos ${ }^{26}$. Con todo, si el monarca tenía a bien aprobar estas medidas extraordinarias, sería conveniente establecer mecanismos de control sobre los fondos librados, asegurándose de que iban a ser utilizados en aquello que justificaba su percepción ${ }^{27}$.

Pero los interesados en formar parte de este proyecto no solo aspiraban mejorar el estado de sus economías, sino que también pusieron sus ojos en objetivos más ambiciosos, entre los que se encontraba el ingreso en las Órdenes Militares. La primera referencia a la posibilidad de obtener un hábito mediante el servicio en esta unidad sirviendo una campaña, la hemos encontrado a finales del mes de abril. Se trataba de un ofrecimiento similar al que se hizo a los sustitutos que sentaron plaza en el Batallón de las Órdenes, en lugar de los caballeros excusados, a cambio de dos. Si bien, no sabemos si se trataba de un ofrecimiento realizado a este individuo a título personal, o por el contrario era una disposición de carácter general, como en el caso de la caballería de las Órdenes Militares ${ }^{28}$. Nos inclinamos a pensar que estas prebendas serían ofrecidas a determinados individuos, en quienes concurrían circunstancias especiales, como motivación para el servicio.

Otro de los escogidos fue D. Francisco de la Lombana, caballero de la orden de Santiago, quien sirvió en el Batallón de las Órdenes la campaña del año 1640 y a su conclusión recibió permiso para retirarse, aunque con la condición de volver cuando se reanudasen las hostilidades. Sin embargo D. Francisco no tenía ninguna

26 “(...) Y algunos de los caballeros que han de ir acompañando la real persona de V.M. en la ocasión de Portugal, suplicaron a V.M. que para poderlo hacer con el lucimiento que la ocasión pide, se les hiciese merced de darles facultad para vender alguna partes de sus mayorazgos y para tomar a censo sobre ellos algunas cantidades, y a otros diferentes medios. Y habiendo bajado las órdenes a este consejo se han reparado algunas (...). Pues reconociendo que por este medio se van deshaciendo todas las fundaciones de mayorazgos, y porque ha mostrado la experiencia que los procedidos de estos medios se consume y gasta sin útil ni conveniencia del servicio de V.M, el consejo no pasa adelante, dejándolo a la real resolución de V.M., pues su intención no es más que los poseedores de estos mayorazgos no disipen sus fundaciones." Consulta de la Cámara en la que da cuenta de algunos despachos que están detenidos. Madrid, 3-6-1641. AHN, Estado, Leg. 6405(2).

27 “(...) Y en caso de que convenga darles estos medios, sirvan solo para el fin que se conceden y no se conviertan, como se ha reconocido, en otros usos de menores atenciones. Y que lo procedido se deposite y gaste con cuenta y razón en lo que fuere necesario para esta ocasión, sin elección de los interesados." Ibídem.

${ }^{28}$ Decreto de S.M. dirigido a la secretaría del consejo de Órdenes, en el que da cuenta de haber hecho merced de hábito a D. Juan de Frías, que va a servir en el Escuadrón de la Nobleza, para la vuelta de la jornada. Madrid, 30-4-1641. AHN, OO.MM, Leg. 108(1), nº 82. 
intención de regresar a su puesto, ya que su deseo era sentar plaza en el Escuadrón de la Nobleza ${ }^{29}$. Tal vez porque el servicio en el Batallón de las Órdenes suponía una asistencia obligatoria, consideró que sirviendo en esta nueva unidad se colmarían mejor sus expectativas profesionales ${ }^{30}$ y personales. Respecto a estas últimas, solicitó que se autorizara el traspaso a un deudo del hábito que tenía ajustado para un hijo por su asistencia en el Batallón (petición que albergaba serias dudas sobre su legalidad, pues era muy probable de que su deseo ocultara una operación venal). Pese a todo, la Junta del Escuadrón de la Nobleza intercedió por D. Francisco, siempre y cuando la persona designada para el hábito acreditara la calidad necesaria ${ }^{31}$. En última instancia se accedió a su demanda, y al año siguiente León de Alzá y de Garbiso, natural de Oyarzun (Guipúzcoa), alcalde mayor de San Luis de Potosí y Río Verde (en Nueva España), ingresó en la orden santiaguista ${ }^{32}$.

En cuanto a los resultados prácticos, pese a los esfuerzos de ese organismo por levantar algún contingente montado, fue incapaz de formar ni una sola compañía. La razón de este fracaso se encuentra en la cancelación del viaje de Felipe IV a Extremadura, hecho que lo cambiaba todo. Al desaparecer la premisa que justificaba la prevención de los hidalgos, su deseo de servir desapareció súbitamente, aunque ello significara que pudieran ser compelidos por otras instancias.

\section{LA GRAN MOVILIZACIÓN DE 1642.}

El año 1642 significó un punto de inflexión en lo relativo a la movilización nobiliaria, pues en esta ocasión Felipe IV tomó la determinación de encaminarse a la frontera. Si el año anterior el hipotético destino era Extremadura, ahora sus miras se volvieron hacia el otro frente peninsular (Cataluña), fijándose el 23 de abril como fecha de salida hacia Aragón. La decisión del rey tuvo un impacto inmediato sobre el segundo estamento, pues a partir de ese momento le iba a resultar mucho más difícil eludir su participación en el esfuerzo bélico común, ya que si el rey

${ }^{29}$ Consulta de la junta de la milicia de las Órdenes sobre la pretensión de D. Francisco de la Lombana y Rojas, caballero de la de Santiago. Madrid, 14-5-1641. AHN, OO.MM, Leg. 4667.

${ }^{30}$ Estas se circunscribían al mando de un galeón de la flota que transportaba la plata hasta Sevilla a la conclusión de la campaña, y a que se hiciera efectiva la merced del empleo de almirante (para la cual había sido consultado hasta en tres ocasiones). Ibídem.

31 Ibídem.

32 AHN, OO.MM, Caballeros-Santiago, Expediente 374. Relación de los servicios de León de Alzá, caballero de la orden de Santiago, gobernador y capitán general del Nuevo Reino de León, en la Nueva España, por nombramiento del virrey de ella. Madrid, 20-3-1666. Archivo General de Indias, Indiferente, Leg. 121/38. 
encabezaba las operaciones militares estaban obligados por ley a acompañarle. Así, desde mediados del mes de marzo se comunicó a los grandes y títulos de Castilla este acontecimiento, a la vez que se requería su asistencia aunque en realidad se trataba de una exigencia camuflada con buenas palabras y la promesa de futuras mercedes para quienes más se implicaran ${ }^{33}$.

La severa derrota que las fuerzas franco-catalanas infligieron al ejército comandado por D. Pedro de Aragón ${ }^{34}$ tuvo graves consecuencias sobre el ánimo de Felipe IV, hasta el punto de temer por la seguridad de la propia Castilla. Su inquietud llegó a tal extremo que, pese a haber abandonado ya la Corte (acontecimiento que se produjo el día 26 de abril) a principios de mayo envió nuevas misivas a la primera nobleza del Reino para que estuviera lista cuando hiciera su entrada en Aragón ${ }^{35}$.

Respecto a la base del estamento privilegiado, el año 1642 también acarreó un incremento de la presión de la Corona por conseguir su asistencia en el campo de batalla. Pese a que en los años anteriores se habían puesto en marcha iniciativas para conseguir este fin, lo cierto es que en ningún momento se tensó la cuerda en exceso. Pero la decisión del monarca de encaminarse a Aragón se tradujo en el primer requerimiento forzoso a este grupo ${ }^{36}$. Del mismo modo, en esta ocasión se dejaron de lado consideraciones de tipo formal y se esgrimieron argumentos de carácter legal, pues los hidalgos tenían unas obligaciones militares inexcusables, siempre y cuando el rey saliera hacia el frente ${ }^{37}$.

${ }^{33}$ Carta del rey al conde de Fuensalida. Madrid, 16-3-1642. SNAHN, Frías, 26/5.

${ }^{34}$ Misceláneos históricos y políticos sobre la guerra de Cataluña desde el año de 1639, por Alberto de Torme y Liori. S.l. s.f. (Marzo 1642). Biblioteca Nacional (En adelante BN), Manuscritos (En adelante Mss), 1927. Fols. 67v-69v. Relación verdadera de la rota y presa del general D. Pedro de Aragón y todo su ejército. S.1., 1642. BN, Mss, 2374. Fols. 531-543.

${ }^{35}$ Carta de Felipe IV al conde de Fuensalida. Aranjuez, 5-5-1642. SNAHN, Frías, 26/6.

${ }^{36}$ Bando para que los caballeros hijosdalgo saliesen a la campaña de Cataluña el año 1642. Madrid, 12-5-1642. BN, Mss, 2474. Fol. 506v.

37 "Por cuanto de orden del rey nuestro señor, Dios le guarde, se han publicado diferentes bandos para que todos los caballeros hijosdalgo estén prevenidos para salir con efecto acompañando su real persona a las fronteras de Cataluña, con sus armas y caballo, en conformidad de las leyes y fueros de España. Y muchos de los caballeros hijosdalgo se pretenden eximir en persona, con excusas y modos afectados, faltando a la obligación que tiene por las leyes y fueros antiguos de estos reinos, y a las de su sangre (que siempre han mantenido y conservado con particular atención los nobles de ellos) de ir acompañando a Su Majestad, manda que todos salgan efectivamente siguiendo a S.M., en conformidad de los bandos antes de este publicados, y debajo de las penas contenidas en las leyes y fueros de estos reinos, contra los caballeros hijosdalgo que desamparan a su rey y señor natural, y no le siguen y acompañan (.......)." Ibídem. En este sentido, fray Benito de Peñalosa refiere que entre los 
Otra de las novedades introducidas se refiere a la dureza de las sanciones contempladas contra los desobedientes, salvo aquellos que no pudieran estar presentes en la jornada real por excusas legítimas. Si en los años anteriores se daba a entender el malestar del monarca con quienes no le asistieran, en términos como "me daré por deservido de vuestra merced", u otros de naturaleza similar, en mayo de 1642 se amenazó con la pérdida de la condición de privilegiado y todos los honores que llevaba aneja ${ }^{38}$.

La decisión de Felipe IV también repercutió en la movilización de los caballeros de hábito, hasta el punto formar un nuevo Batallón de las Órdenes, comandado por el conde de Monterrey con el título de caudillo mayor, que reunió a cerca de 900 efectivos $^{39}$. Esta circunstancia, junto con la pervivencia del Escuadrón de la Nobleza, hizo que se reprodujeran las disputas entre ambas entidades administrativas. En este caso, las diferencias que tuvieron lugar en 1641 con motivo del servicio militar de determinados caballeros de hábito, se reprodujeron por el dinero procedente de la relevación de la presencia personal.

La tenacidad de la Junta del Escuadrón de la Nobleza por hacerse con el control de estas sumas puede venir explicada por sus dificultades financieras, pues a diferencia de otros organismos no tenía consignada ninguna cantidad para hacer frente a los gastos que acarrearía su puesta en marcha, a pesar de que todos sus integrantes servirían sin sueldo y, al menos en teoría, se costearían su equipo. Con todo, un número considerable de hidalgos no se encontraba en condiciones de asumir un desembolso de esa magnitud, de modo que la Real Hacienda debería facilitar los medios necesarios para que pudieran cumplir con su deber.

privilegios de los que gozan los hidalgos, se encuentra el no poder ser compelidos a ir a la guerra "si no es cuando fuere la persona del rey, y entonces se les ha de hacer saber." PeÑALOSA, B. de (1629). Libro de las cinco excelencias del español que despueblan a España para su mayor potencia y dilación. Pamplona, Fol. 88r.

38 “(...) y los que faltaren, y contravinieren a la ejecución y cumplimiento de lo referido, queden privados de los honores y preeminencias que como a tales nobles y caballeros hijosdalgo les pertenecen. Para los que lo son de privilegio, le pierdan enteramente por su vida y queden en el estado que tenían antes que se les concediese, sin embargo de cualesquier cláusulas generales y especiales y derogaciones de leyes que contengan, y de cualquier causa o razón por que se hayan concedido, ora sea en remuneración de servicios, ora vía de contrato. Y los de sangre no puedan gozar, ni gocen en ninguno de los lugares de estos reinos de los oficios honrosos que por leyes y costumbres se suelen dar, y dan, a los hijosdalgo; ni tener hábitos de las ordenes militares, sino es constando que han acudido al llamamiento de S.M., acompañando su real persona, o que están justamente dados por impedidos por los ministros y personas a quien SM lo ha cometido o cometiere (...)." Ibídem.

39 Sobre este particular véase: JimÉnEZ MoREnO, A. (2011). «Nobleza, guerra y...», op. cit. pp. 586-627. 
A la hora de buscar explicaciones a sus apuros, no podemos ignorar la obligación de los caballeros de hábito que pretendían eludir la presencia en la caballería de las Órdenes Militares mediante la presentación de un sustituto, de entregar al receptor de la Junta de la Milicia de las Órdenes la cantidad en que se había tasado esta modalidad de servicio (120 ducados en plata o 300 en vellón $)^{40}$. No obstante, y pese a tratarse de una ilegalidad, la Junta del Escuadrón de la Nobleza percibió cantidades por este concepto, que correspondían al organismo movilizador de los caballeros cruzados. Pero esto no fue lo más grave, pues haciendo gala de una evidente deslealtad, aceptó sumas inferiores a las exigidas por la Junta de la Milicia de las Órdenes a cambio de evitar la asistencia personal en el Batallón ${ }^{41}$.

Ante tal intromisión en sus competencias, el monarca ordenó que todos los caballeros de hábito que no fueran a servir en persona depositaran los 120 ducados en plata ante el receptor de dicha junta, y que la del Escuadrón de la Nobleza devolviera las cantidades percibidas de forma indebida ${ }^{42}$. En virtud de esta resolución, el 30 de abril se promulgó un real decreto dictaminándose que quienes no prestaran servicio personal en el Escuadrón de la Nobleza, presentaran un sustituto, o mejor aún su equivalente en metálico, ante la Junta de la Milicia de las Órdenes. Del mismo modo, se prohibía que la Junta del Escuadrón ingresara un solo maravedí por ese concepto ${ }^{43}$.

Lo cierto es que con aportaciones tan magras sería harto complicado asegurar su continuidad. Pero más o menos por esas fechas la Corona cedió a sus gestores una

${ }^{40}$ Consulta de la junta de la milicia de las Órdenes sobre las cantidades que la junta del Escuadrón de la Nobleza ha beneficiado de algunos caballeros de hábito. Madrid, 26-4-1642, AHN, OO.MM, Leg. 4668.

${ }^{41}$ Por ejemplo, D. Pedro González de Mendoza, D. Juan de Zárate y Porres y D. García de Herrera, entregaron 250 ducados de vellón el primero, y 200 los otros dos, al receptor de la Junta del Escuadrón de la Nobleza por ser relevados de servir en persona en esta unidad. Mientras que el secretario Pedro de Berberana, caballero calatravo, depositó 200 ducados de vellón por el mismo concepto. Pliego donde se ha de tomar la razón de las certificaciones del sr. secretario D. Cristóbal de Medina, de la cantidad de maravedíes que han pagado algunos caballeros de hábito por haberles relevado la junta de la Nobleza de ir a servir personalmente. S.l., s.f. (1642). AHN, OO.MM, Leg. 4644.

42 “(...) Parece que se compongan todos por esa junta [la del Batallón de las Órdenes] a pagar en plata, que es lo mejor. Y he mandado a la del batallón [de la Nobleza] que les restituya lo que por allí hubieren dado." Consulta de la junta de la milicia de las Órdenes...26-4-1642.

${ }^{43}$ Consulta de la junta del Escuadrón de la Nobleza sobre las cantidades entregadas por algunos caballeros de hábito. Madrid, 6-5-1642. AHN, OO.MM, Leg. 4668. 
serie de efectos ${ }^{44}$, para que con su producto pudieran asumir las deudas en que habían incurrido. El primero de ellos era la venta del oficio de contador de la razón general de la ciudad de Sevilla ${ }^{45}$, que aportaría 30.000 ducados a las arcas de este organismo $^{46}$. Otro de los expedientes consignados a este fin fue la venta de un asiento en las Cortes, a lo que opuso la Cámara de Castilla ${ }^{47}$. Entre las ciudades interesadas en su adquisición se encontraban Palencia (que ofrecía 60.000 ducados pagados en seis años), Jerez de la Frontera (85.000 ducados) y Málaga (100.000 ducados). A pesar de que la oferta de Palencia era la menor de las tres, contaba con más posibilidades de ser la ganadora, pues los trastornos que ocasionaría a la población serían mucho menores que los de sus rivales (al tratarse de una suma

${ }^{44}$ No obstante, durante los años anteriores ya se habían producido operaciones de esa naturaleza, si bien a una escala mucho menor. Por ejemplo, en agosto de 1641 se hizo merced a D. Bernardo Calderón de la Barca, notario del secreto de la Inquisición de Sevilla, de un título de secretario, para que pudiera servir en ella con dicho empleo, a cambio de 2.000 ducados de vellón para ayudar a la formación del Escuadrón de la Nobleza. Y en 1642 Toribio Pérez de Bustamante fue honrado con una vara de alguacil de Corte, a cambio de asumir el coste de 200 caballos para montar a los integrantes de la mencionada unidad. Si bien el despacho de estas mercedes se complicó, pues la Cámara hizo reparo en su concesión y fueron gratificados con otras prebendas. Consulta de la Cámara sobre la pretensión de D. Bernardo Calderón de la Barca. Madrid, 17-1-1644. AHN, Consejos, Leg. 44294430, $\mathrm{n}^{\circ}$ 9. Consulta de la Cámara sobre la pretensión de Toribio Pérez Bustamante. Madrid, 6-31647. AHN, Consejos, Leg. 4430, nº 16.

${ }^{45}$ Se trata de un empleo vinculado a la corporación municipal, entre cuyas tareas se encontraba el control e intervención del libro de caja de los gastos del ayuntamiento. BERNAL, A.M. (1978). «Haciendas locales y tierras de propios: funcionalidad económica de los patrimonios municipales (siglo XVI-XIX)». Hacienda Pública Española, 55, pp. 285-312. MARTíneZ RUIZ, J.L. (1988). «La reforma de la Contaduría municipal de Sevilla y la introducción del libro de caja (1567)». Revista Española de Financiación y Contabilidad, 56, pp. 334-349. GARCÍA RuIPÉREZ, M. (2005). «Los contadores municipales en la Corona de Castilla (siglos XIV-XVIII)». Revista Española de Historia de la Contabilidad, 2, pp. 53-100.

46 “....) Y por resolución de consulta de la junta del Escuadrón de la Nobleza de 10 de marzo del año pasado de 1642, fue servido S.M. de aplicarla, para las prevenciones de las compañías que había de montar, el medio del oficio [de contador] de la razón de la ciudad de Sevilla." Sin embargo, un año después únicamente había 10.000 ducados, pues el comprador de este empleo estaba esperando el título que validara la operación, y hasta que no se le despachara no entregaría el resto. Papel del secretario Cristóbal Medina a D. Francisco de Alarcón, en el que da cuenta de los medios de la junta del Escuadrón de la Nobleza para acudir a las ocasiones presentes. Madrid, 18-3-1643. AHN, OO.MM, Leg. 6405(2).

47 “(...) Cuanto quiera que V.M. tiene derecho a aumentar dos votos en Cortes, todavía se reconoce el daño que de este crecimiento se sigue, porque es fuerza que en cada una de las ayudas de costa que se reparten al Reino, se recrezca lo que es forzoso dar a los procuradores de Cortes que se añadieren." Consulta de la Cámara sobre la resolución que V.M. se sirvió de tomar a lo consultado por la junta del Escuadrón de la Nobleza, sobre el voto en Cortes que pide Palencia. Madrid, 29-51642. AHN, Consejos, Leg. $4428, n^{\circ} 52$ 
inferior, la carga fiscal que debería soportar la ciudad para reunirla sería menos gravosa). Pese a todo, se albergaban serias dudas respecto a la capacidad de la oligarquía palentina para aprestar la cantidad acordada, ya que no había satisfecho ninguno de los servicios solicitados por la Corona hasta ese momento ${ }^{48}$.

En cualquier caso, resulta muy curioso que los miembros de las Órdenes Militares alistados en el Escuadrón, de repente empezaran a ser relevados de acudir en persona a cambio de dar un sustituto o entregar una cantidad en efectivo. Esta circunstancia vendría a dar la razón a los integrantes de la Junta de la Milicia de las Órdenes, quienes desde el primer momento sostuvieron que la motivación que se encontraba detrás del deseo de servir en el Escuadrón era eludir sus obligaciones militares, pues sospechaban que el monarca nunca abandonaría la Corte para dirigirse al frente, y de este modo no se verían obligados a servir. Pero la firme determinación de Felipe IV de dirigirse a Cataluña amenazó con demoler su entramado, y una vez que se determinó la fecha del viaje hacia a la frontera oriental, buscaron excusar su presencia personal a través de la Junta del Escuadrón de la Nobleza. Una vez conseguido este objetivo, el siguiente paso era conseguir que el sustituto supusiera el menor desembolso posible, y por ello pusieron sus miras en ese organismo.

Otro de los puntos que agudizó la rivalidad entre ambas instituciones fue la pugna por incluir a los hidalgos en sus filas, pues los testimonios recogidos dan a entender que eran un bien escaso. La Junta del Escuadrón de la Nobleza se creía con derecho a registrarlos porque tenían la obligación de acompañar al rey si se ponía al frente de las tropas, mientras que la del Batallón de las Órdenes consideraba que, si bien no estaba en condiciones de monopolizar su asistencia, se les debía conceder libertad para servir en la caballería cruzada, ya que se había ofrecido el hábito con carácter general a todos los hidalgos que sirvieran esa campaña en sus filas ${ }^{49}$. En esta ocasión, el monarca dio la razón a la Junta de las

48 “(...) Y en caso de que se llegue a ajustar la conveniencia del acrecentamiento de voto en Cortes, se ajuste primero lo que en esta materia tiene representado a V.M. el consejo de Hacienda, y luego se pase al servicio que ha de hacer la comunidad, y que su paga y medios de donde hubiere de salir sean sin perjuicio y daño de lo público, pues [de lo contrario] la utilidad solo vendrá a ser en los capitulares. Y en Palencia hay mayores causas para que se ajuste este punto, porque según las noticias que hay, es de tan corta disposición que habiéndosele pedido en esta ocasión sirva con 100 soldados, pagados por seis meses en plata, avisa su corregidor que no tiene medio ni forma si no es para servir más que con 20." Ibídem.

49 "En el batallón de las Órdenes solo se admiten los caballeros de ellas que son hábiles para servir y no tienen ocupación del servicio de V.M. que les releva de esta obligación. Y se suple el número de los impedidos y ocupados con personas de conocida calidad, merecedores y capaces del premio que V.M., con su acostumbrada grandeza, les da, de hábito para pasada la campaña de este 
Órdenes, prohibiendo su saca del Batallón siempre y cuando desearan servir en él ${ }^{50}$.

Pese a todas las dificultades que hemos referido, en esta ocasión se consiguió aprestar seis compañías, cuyos capitanes fueron: el Conde Duque de Olivares (aunque el responsable de ella era su teniente, D. Juan de Vega y Menchaca, conde de Grajal y caballero de la orden de Santiago), los duques de Ariscot, Pastrana y Veragua, el conde de Oropesa y el marqués de La Hinojosa (que recordemos era uno de los integrantes de la Junta del Escuadrón de la Nobleza ${ }^{51}$. Sin embargo, a diferencia de la caballería de las Órdenes, que sí tomó parte activa en los combates, su presencia en el frente debió ser testimonial y circunscrita a la protección del monarca durante su estancia en el Reino de Aragón, puesto que no hemos encontrado evidencias documentales sobre su participación en las operaciones militares.

En cuanto a las recompensas, la salida del monarca hacia la Corona de Aragón supuso un esfuerzo sin precedentes. Ese año, si utilizamos una expresión coloquial, "se tiró la casa por la ventana" para ganarse las voluntades los hidalgos. Lo cierto es que la ocasión lo merecía, pues un acontecimiento tan importante como la presencia del rey al frente de sus tropas (circunstancia que no se producía desde el año 1557, cuando Felipe II estuvo presente en la batalla de San Quintín), exigía el empleo de todos los medios disponibles para aprestar unas fuerzas acordes con la calidad de su comandante.

Dentro de las mercedes ofrecidas a los soldados del Escuadrón de la Nobleza se encontraban los hábitos de las Órdenes Militares. Este hecho nos llevaría a replantearnos el papel que se ha adjudicado a tales honores, pues en general se ha pensado que eran una recompensa a largos años de servicio (de muy diversa naturaleza, no exclusivamente los prestados con las armas), en una clara secuencia: primero se hacían méritos y luego se recibía la merced. Ahora, pese a que se repite dicho patrón, se utilizaron estos honores como señuelo para atraer a los potenciales

año, de que hay número muy considerable. Y se tiene por imposible conseguir este fin si V.M. no se sirve de mandar que los hijosdalgo llamados y prevenidos en la ocasión presente cumplan con servir en esta milicia, porque sucede que algunos son molestados por otras vías." Consulta de la junta de la milicia de las Órdenes para que los hidalgos que vienen a servir, tengan elección de poder hacerlo en el Batallón de ellas. Madrid, 5-6-1642. AHN, OO.MM., Leg. 4668.

${ }^{50}$ Ibídem.

${ }^{51}$ Relación de algunos caballeros de hábito que antes de tenerle se alistaron en el escuadrón de la nobleza, a cuya causa han sido excusados en el batallón de las órdenes, dándoles por libres del llamamiento de ellas y a sus fiadores, del pago de los 300 ducados. S.1., s.f. (mayo de 1642). AHN, OO.MM, Leg. 4668 
reclutas, a la vez que se reducía el tiempo de servicio a unos meses. Si bien se trataba de una oferta que no estaba al alcance de todos, sino que los aspirantes debían acreditar hidalguía (algo obvio por otra parte, pues en teoría la unidad debía estar compuesta por individuos de esta condición) o una dilatada trayectoria militar que incluyera, como mérito preferente, experiencia en la caballería. De esta forma, nos inclinamos a pensar que debió de producirse algo parecido a lo que tuvo lugar con el Batallón de las Órdenes ese mismo año: una auténtica avalancha de solicitudes por ingresar en sus filas ${ }^{52}$. En lo relativo al Escuadrón de la Nobleza, hemos podido identificar 27 concesiones de hábito por la prestación de servicios en esta unidad, que si bien se trata de una cifra no demasiado elevada teniendo en cuenta las mercedes despachadas en esos años ${ }^{53}$, ilustra a la perfección las intenciones del Conde Duque con respecto al segundo estado, y más en concreto a sus bases.

Al contrario de lo acontecido con las prebendas ofrecidas a quienes sirvieran esa campaña en el Batallón de las Órdenes, en este caso la mayoría de ellas fueron a parar a las personas que realizaron el servicio, lo que se produjo en 19 situaciones (74\%). En cuanto al resto, en siete supuestos el hábito se despachó para un tercero, bien un familiar directo (sobrino o hijo), bien la persona que contrajera matrimonio con alguna pariente femenina (nieta o sobrina), con la clara intención de mejorar (o según el caso consolidar) la situación del clan. En último lugar, no hemos encontrado evidencias de la concesión de la merced en uno de los supuestos, ni de que se hiciera efectiva en otro aspirante.

Respecto a la orden elegida por los futuros caballeros, la mayor parte de ellos (22) se decantaron por la de Santiago, mientras que las otras dos aparecen mucho menos representadas, pues Alcántara contabiliza únicamente tres casos y Calatrava uno. Este desequilibrio vendría a confirmar la supremacía de la orden jacobea sobre las demás, por lo menos en cuanto a número integrantes, ya que gozaba de

52 En el caso de la caballería de las Órdenes Militares las cifras hablan por si solas, pues hemos podido documentar como se prometieron cerca de medio millar de hábitos para quienes se alistaran en ella. Sin embargo solo unos pocos vieron colmadas sus pretensiones, pues menos del $20 \%$ fueron despachados, y la mayor parte no fueron a parar a quienes habían prestado servicio en el Batallón. JiMÉNEZ MoRENO, A. (2011). «Nobleza, guerra y..»,. Op. cit. pp. 794-865.

53 El periodo comprendido entre 1641 y 1649 , en el cual fueron despachados la mayoría de los hábitos concedidos por haber servido en el Escuadrón de la Nobleza, se caracterizó por ser de los más prolíficos en cuanto a la concesión de estas mercedes. Según ha puesto de manifiesto Postigo Castellanos, en 1641 se tramitaron 173 hábitos y en 1649, 124; y la media anual de esos años ascendió a 139. Postigo Castellanos, E. (1998). Honor y privilegio en la Corona de Castilla. El Consejo de las Órdenes y los caballeros de hábito en el siglo XVII. Valladolid, Junta de Castilla y León, p. 199. 
una mayor estimación social. También nos llama la atención que casi la mitad (siete) de los 17 supuestos en los que hemos conseguido averiguar la compañía en la que sirvió el aspirante, lo hicieran en la del Conde Duque de Olivares, y que los nueve agraciados restantes se repartieran en cuatro compañías (la del duque de Veragua con cinco, la del conde de Oropesa con dos, la del duque de Ariscot con otros tantos, y la del marqués de la Hinojosa con uno; sin que hayamos podido encontrar ninguno en la del duque de Pastrana.

Sobre la ocupación profesional de quienes recibieron un hábito por servir en el Escuadrón de la Nobleza, sólo hemos conseguido encontrar referencias de una minoría, que no abarca ni el 33\%, ocho supuestos. La actividad más repetida es la de oficial del ejército, pues hemos identificado a tres capitanes de infantería y otro de caballos corazas. En segundo lugar, con dos ejemplos, se encuentran dos regidores municipales (uno de Soria y otro de Madrid); y a continuación un familiar del Santo Oficio, un individuo que era regidor (también de la capital del Reino) y capitán de infantería, y una persona que servía como paje (en este caso del Conde Duque de Olivares, que suponemos sentaría plaza movido por los vínculos clientelares que le unían a su señor). Si bien se trata de una muestra exigua, sobre la que no podemos establecer conclusiones generales se observa que, de una manera parecida a lo sucedido con el Batallón de las Órdenes levantado en 1642, los oficiales reformados encontraron atractiva esta propuesta y decidieron formar parte de ella. De la misma manera, los empleos de regidor y familiar del Santo Oficio, muy vinculados a las oligarquías locales demuestran que, en una secuencia idéntica a la de la caballería de las Órdenes Militares, el proyecto podía ser útil para atraer a los cuadros inferiores del estamento privilegiado y facilitar su ingreso en estas instituciones.

Pese a que la formación de ambas unidades eran pasos en la dirección correcta para vincular al segundo estado con la guerra y, al mismo tiempo, reforzar los lazos que unían a las Órdenes Militares con la profesión de Marte, lo cierto es que se trataba de gotas de agua dentro de la inmensidad del océano. Según nuestro criterio, gran parte de culpa hay que atribuírsela al Consejo de Órdenes, pues este organismo mostró sus reservas a colaborar en unos proyectos que, al incrementar de forma notable el número de caballeros de hábito, acarrearían la depreciación de tan preciados honores, erosionando las bases sobre las que se cimentaba su poder.

Lo acontecido durante el año 1642 es un claro ejemplo de lo que pudo haber sido un grandioso éxito para la Corona (sobre todo para el Conde Duque y sus proyectos reformistas, en un momento en el que su figura política estaba más cuestionada que nunca y sus enemigos se preparaban para asestarle el golpe definitivo, acontecimiento que se produjo a principios de enero de 1643) y se 
quedó prácticamente en nada. Así, el balance final ofrece unos resultados mucho más modestos, que si bien tienen cierta importancia, pues se trata de hábitos concedidos por méritos contraídos con las armas, fueron actuaciones aisladas, sin continuidad en el tiempo y que no modificaron las estructuras vigentes. Tampoco podemos dejar de reseñar que, a diferencia de otros designios, no se obligó a los pretendientes de los hábitos a servir durante un periodo más o menos largo a cambio de la merced, buscando que hicieran carrera en el ejército. Al contrario (con la salvedad de los oficiales reformados y algunos individuos que deseaban continuar haciéndolo), lo habitual era que una vez cumplido el tiempo de servicio se abandonara todo contacto con la profesión militar, y el sujeto en cuestión retomara sus ocupaciones cotidianas.

El gran esfuerzo realizado en 1642 pasó factura a la Junta del Escuadrón de la Nobleza, que a duras penas pudo continuar su actividad. El principal problema al que se enfrentaba era de carácter financiero, pues los arbitrios consignados para su mantenimiento no dieron los frutos esperados. Ante este desalentador cuadro lo único que podría garantizar su sostenimiento era la consignación de nuevas rentas. Una de las pocas que aún no había sido comprometida era la de la sosa y la barrilla $^{54}$, que al parecer generaba unos ingresos anuales de 10 millones de maravedíes (26.666 ducados). Durante las semanas siguientes la situación se deterioró aún más, hasta el punto de que los acreedores de la Junta del Escuadrón de la Nobleza amenazaron con proceder contra sus funcionarios, exigiendo la entrega de sus bienes para liquidar las deudas pendientes ${ }^{55}$.

Por si esto no fuera suficiente, a finales del mes de abril se reiteró la orden promulgada para que todos los caballeros de hábito que habían sido relevados de servir en persona, a cambio de pagar el coste de un sustituto, depositaran la cantidad correspondiente ante el receptor de la Junta de la Milicia de las Órdenes.

\footnotetext{
${ }^{54}$ La barrilla es una planta que crece en terrenos salados, y sus cenizas (ricas en sales alcalinas) sirven para obtener la sosa; además, era utilizada para fabricar vidrio, mientras que la sosa se empleaba en la fabricación de jabón. En cuanto al origen de la figura fiscal en cuestión, surgió en virtud de dos reales cédulas promulgadas en 1621 y 1634, según las cuales se gravaba con seis reales de vellón cada quintal de barrilla, y con tres cada quintal de sosa, como uno de los medios con los que pagar los servicios de millones. Domínguez OrTiz, A. (1960). Política y hacienda de Felipe IV. Madrid, Editorial de Derecho Financiero, pp. 219-220. Velasco HeRnÁndEZ, F. (2002). «La presión fiscal en el siglo XVII en el Reino de Murcia». Espacio, Tiempo y Forma. Serie IV, Historia Moderna, 15, pp. 75-92. VelasCo HERnÁNDEZ, F. (2004). «La sosa-barrilla: una señal del campo de Cartagena en los siglos XVI al XIX». Revista murciana de antropología, 10, pp. 145-158.

55 Papel del secretario Cristóbal Medina al secretario D. Antonio Carnero, sobre los medios dispuestos para levantar el Escuadrón de la Nobleza. Madrid, 27-5-1643. AHN, Estado, Leg. 6405(2).
} 
Ambas circunstancias supusieron un golpe definitivo, y a finales del mes de septiembre se puso fin a sus actividades ${ }^{56}$. Pero su desaparición no se debió únicamente a los problemas económicos, sino que también influyó en ello el cambio de mentalidad operado tras la caída del Conde Duque de Olivares, y la relajación de los compromisos exigidos al segundo estado. A partir de ese momento se optó por una política mucho más suave con respecto a la contribución de la nobleza al esfuerzo bélico común, caracterizada por el pactismo. Del mismo modo, la presencia de los privilegiados en el frente había supuesto, en general, más un engorro que una ayuda ${ }^{57}$. Así que se optó por circunscribirlo a aquellas situaciones en las que realmente supusiera algo provechoso.

\section{CONCLUSIONES.}

Uno de los aspectos sobre los que debemos hacer hincapié es la imposibilidad de definir al estamento privilegiado desde una única perspectiva, pues se trata de un conglomerado en el que se dan cita individuos de muy diversa naturaleza, cuyas motivaciones no tenían por qué ser coincidentes. Del mismo modo, en algunos de ellos concurría más de una categoría nobiliaria, circunstancia que reafirmaría dicha diversidad, y que podía suponer (como de hecho ocurrió) una fuente de conflictos.

Pese a los esfuerzos de la administración olivarista por reforzar el vínculo que unía al segundo estado con la carrera de las armas, lo cierto es que la vieja aspiración de conseguir su participación personal no era siempre la mejor opción. De hecho se trataba de una modalidad de servicio que coexistía con otras, y desde un punto de vista meramente operativo la asistencia al monarca con las armas sólo era útil en determinadas circunstancias (en concreto si era prestado por quienes tenían vocación castrense, o acreditaban experiencia en la guerra). De la misma manera, en otros supuestos (sobre todo en lo relativo a grandes y títulos) el poder real podía obtener un mayor beneficio a través otros caminos, que no suponían la presencia del privilegiado en el campo de batalla.

También debemos tener en cuenta que el servicio militar de la nobleza iba ligado a que el monarca encabezara sus ejércitos en el campo de batalla. Pese a que a partir de 1632-1633 se empezó a plantear esta posibilidad, no fue hasta 1635

${ }^{56}$ Consulta de la junta de la milicia de las Órdenes sobre que se releve de pagar aquí a los caballeros de hábito que cumplieron el año pasado de 1642 con pagar la cantidad que se les repartió por la junta del Escuadrón de la Nobleza. Madrid, 24-9-1643. AHN, OO.MM, Leg. 4668.

57 “(...) me ha parecido ordenaros excuséis venir a acompañarme hasta otro aviso, que será cuando con mayor utilidad pueda lucir lo que siempre esperaré de vos." Carta del rey a D. Jerónimo Garcés de Mendoza, conde de Priego, en la que le manda suspenda el pasar a la Corte para irle sirviendo. Madrid, 15-5-1643. SNAHN, Priego, 3/32. 
cuando tomó cuerpo (y aun hubieron de pasar otros siete años para que se hiciera realidad). Su falta de concreción era un argumento que fortalecía la posición de los nobles más reticentes a servir en persona, pero no era menos cierto que parte de ellos no tenía ningún vínculo con la profesión de Marte, desarrollando su actividad profesional en ámbitos ajenos a ella, y lo más probable es que no hubieran empuñado un arma en su vida. Si tenemos en cuenta estas consideraciones, resulta poco coherente sostener el argumento habitual de la pérdida de los valores guerreros de la nobleza, pues es imposible perder algo que no se ha tenido nunca. Pero esto no quiere decir que no pudieran ser útiles mediante otras formas de asistencia. En oposición a este grupo, otro segmento del segundo estado continuó muy vinculado a la profesión militar en su vertiente más tradicional, desde grandes y títulos hasta simples hidalgos.

Si bien a la hora de juzgar la contribución nobiliaria a las necesidades bélicas de la monarquía española debemos hacerlo de una perspectiva más compleja, que tenga en cuenta factores como: las relaciones de poder, la negociación, las recompensas ofrecidas a cambio del servicio o la situación de cada linaje, que no han sido valoradas en su justa medida, más allá de su voluntad o negativa a colaborar con la Corona.

Según nuestro criterio, tanto el Escuadrón de la Nobleza como el Batallón de las Órdenes fueron unidades creadas para que hidalgos y caballeros de hábito prestaran el servicio militar al que estaban obligados en función de sus prerrogativas. Pese a que se trataba de una empresa que acarreó importantes beneficios, sobre todo desde el punto de vista psicológico y ejemplarizante, no se tuvo en cuenta (o se ignoró de forma deliberada) que algunos privilegiados reunían en sus personas ambas realidades. Esta circunstancia generó una agria disputa entre los organismos encargados de su formación, en cuya base se encontraba dirimir cual de ellas estaba por encima.

Pese a sus limitados efectos, la constitución de estas dos fuerzas montadas vino a dar la razón al Conde Duque de Olivares y a sus proyectos destinados a constituir una nobleza de servicio, basada en una inquebrantable fidelidad a la Corona, donde la utilización de los hábitos de las Órdenes Militares constituyó la piedra angular de tales iniciativas, destinadas a vigorizar la relación entre la nobleza y la guerra. Pues dichas mercedes (aunque también se recurrió a otro tipo de gratificaciones, como empleos de todo tipo o medidas destinadas a mejorar su situación económica) consiguieron atraer al servicio militar a individuos pertenecientes a los cuadros inferiores del estamento privilegiado y también a soldados veteranos (oficiales del ejército y la armada, tanto en activo como reformados), quienes de otra manera muy probablemente no se habrían animado a hacerlo. 
En definitiva, aunque se trataba de dos expedientes que indicaban el camino a seguir para solucionar parte de los problemas que afectaban a la maquinaria militar española, las circunstancias (en concreto la incapacidad de la Corona para remunerar a todos los que arriesgaban su vida en el campo de batalla, pero también la caída en desgracia su principal promotor) impidieron explotar todas las posibilidades que ofrecían.

\section{ANEXO. HÁBITOS CONCEDIDOS POR SERVIR EN EL ESCUADRÓN DE LA NOBLEZA (1641-1642).}

\begin{tabular}{|c|c|c|c|c|}
\hline Nombre & Compañía & Orden & Año & Destinatario Final \\
\hline $\begin{array}{l}\text { D. Alonso de Miranda (Regidor } \\
\text { Perpetuo de Soria) }\end{array}$ & $\begin{array}{l}\text { Conde Duque de } \\
\text { Olivares }\end{array}$ & Santiago & 1655 & Idem. \\
\hline D. Alonso González y de Mejía & Duque de Veragua & Santiago & 1643 & Idem. \\
\hline $\begin{array}{l}\text { D. Antonio Correa de Castro y } \\
\text { Lorca (Familiar del Santo Oficio) }\end{array}$ & $\begin{array}{l}\text { Conde Duque de } \\
\text { Olivares }\end{array}$ & Santiago & 1646 & Idem. \\
\hline D. Antonio de Herrera & $i ?$ & Santiago & 1696 & $\begin{array}{l}\text { D. Pedro del Águila } \\
\text { Egas }\end{array}$ \\
\hline D. Diego de Arnalte y Marañón & ¿? & Santiago & 1661 & Idem. \\
\hline D. Diego de Ayala y Tello & Duque de Ariscot & Santiago & 1648 & Idem. \\
\hline D. Diego González & $\begin{array}{l}\text { Conde Duque de } \\
\text { Olivares }\end{array}$ & Santiago & 1646 & $\begin{array}{l}\text { D. Fernando de } \\
\text { Henao Mojaraz y } \\
\text { González }\end{array}$ \\
\hline $\begin{array}{l}\text { D. Facundo Andrés Cabeza de } \\
\text { Vaca }\end{array}$ & $\begin{array}{l}\text { Conde Duque de } \\
\text { Olivares }\end{array}$ & Santiago & 1643 & Idem. \\
\hline $\begin{array}{l}\text { D. Francisco de Aguiar y de } \\
\text { Cangas (Paje del Conde Duque } \\
\text { de Olivares }\end{array}$ & $\begin{array}{l}\text { Conde Duque de } \\
\text { Olivares }\end{array}$ & Santiago & 1646 & Idem. \\
\hline $\begin{array}{l}\text { D. Francisco de Olivares y } \\
\text { Figueroa (Capitán de Caballos } \\
\text { Corazas) }\end{array}$ & ¿? & Santiago & 1641 & Idem. \\
\hline $\begin{array}{l}\text { D. Francisco Ramírez de La } \\
\text { Trapera }\end{array}$ & Duque de Veragua & Santiago & ¿? & Idem. \\
\hline D. Gonzalo de Rojas Carvajal & Conde de Oropesa & Calatrava & 1646 & Idem. \\
\hline D. Iñigo López de Mendoza & ¿? & Santiago & 1641 & Idem. \\
\hline D. Jerónimo Manrique de Lara & ¿? & Alcántara & 1641 & $\begin{array}{l}\text { D. Jerónimo } \\
\text { Manrique de Lara } \\
\text { de Los Ríos }\end{array}$ \\
\hline D. José de Bustamante & Duque de Veragua & ¿? & ¿? & \\
\hline $\begin{array}{l}\text { D. Juan Bautista Enríquez de } \\
\text { Villacorta }\end{array}$ & $\begin{array}{l}\text { Duque de Ariscot } \\
\text { (Alférez de La } \\
\text { Compañía) }\end{array}$ & Santiago & 1649 & Idem. \\
\hline $\begin{array}{l}\text { D. Juan de Falla y Espinosa } \\
\text { (Regidor de Madrid) }\end{array}$ & ¿? & Santiago & 1652 & Idem. \\
\hline D. Juan de Frías & $\begin{array}{l}\text { Conde Duque de } \\
\text { Olivares }\end{array}$ & Santiago & 1673 & $\begin{array}{l}\text { D. Pedro Juan Frías } \\
\text { de La Vega }\end{array}$ \\
\hline $\begin{array}{l}\text { D. Juan de Ochandiano (Regidor } \\
\text { de Madrid y Capitán de } \\
\text { Infantería) }\end{array}$ & ¿? & Alcántara & 1686 & $\begin{array}{l}\text { D. José de Palacios } \\
\text { Villamor }\end{array}$ \\
\hline
\end{tabular}




\begin{tabular}{|c|c|c|c|c|}
\hline D. Juan de Rozas y Escalera & ¿? & Santiago & 1641 & Idem. \\
\hline D. Juan de Solís Mejía & Marqués de La Hinojosa & Santiago & 1655 & $\begin{array}{l}\text { D. Eugenio de Los } \\
\text { Ríos y Vozmediano }\end{array}$ \\
\hline $\begin{array}{l}\text { D. Juan del Río y Rodríguez de } \\
\text { Ledesma } \\
\text { (Capitán de Infantería) }\end{array}$ & ¿? & Santiago & 1642 & Idem. \\
\hline $\begin{array}{l}\text { D. Luis de Quintanilla y } \\
\text { Contreras } \\
\text { (Capitán de } \\
\text { Infantería) }\end{array}$ & Conde de Oropesa & Santiago & 1643 & Idem. \\
\hline $\begin{array}{l}\text { D. Luis Gallo y Gutiérrez } \\
\text { D. Pedro González de Mendoza y } \\
\text { Zapata }\end{array}$ & $\begin{array}{l}\text { Duque de Veragua } \\
i ?\end{array}$ & $\begin{array}{l}\text { Alcántara } \\
\text { Santiago }\end{array}$ & $\begin{array}{l}1643 \\
1643\end{array}$ & $\begin{array}{l}\text { Idem. } \\
\text { Idem. }\end{array}$ \\
\hline D. Rafael Guillén del Castillo & Duque de Veragua & Santiago & 1688 & $\begin{array}{l}\text { D. Lope Fernández } \\
\text { de Rioja y de } \\
\text { Fuentes }\end{array}$ \\
\hline $\begin{array}{l}\text { D. Rodrigo de Ocio y de La } \\
\text { Carrera } \\
\text { (Capitán de Infantería) }\end{array}$ & $\begin{array}{lll}\text { Conde } & \text { Duque } & \text { de } \\
\text { Olivares } & & \end{array}$ & Santiago & 1649 & Idem. \\
\hline
\end{tabular}

